Article

\title{
Trichinella spiralis Excretory-Secretory Products Stimulate Host Regulatory T Cell Differentiation through Activating Dendritic Cells
}

\author{
Xi-Meng Sun ${ }^{1}$, Kai Guo ${ }^{1}{ }^{\circledR}$, Chun-Yue Hao ${ }^{1}$, Bin Zhan ${ }^{2}{ }^{\circledR}$, Jing-Jing Huang ${ }^{1}$ \\ and Xinping Zhu ${ }^{1, *}$ \\ 1 Department of Medical Microbiology and Parasitology, School of Basic Medical Sciences, Capital Medical \\ University, Beijing 100069, China; sunximeng@ccmu.edu.cn (X.-M.S.); guokai223@outlook.com (K.G.); \\ haochunyue1993@126.com (C.-Y.H.); huangjj@ccmu.edu.cn (J.-J.H.) \\ 2 Department of Pediatrics, National School of Tropical Medicine, Baylor College of Medicine, \\ Houston, TX 77030, USA; bzhan@bcm.edu \\ * Correspondence: zhuxping@ccmu.edu.cn
}

Received: 6 September 2019; Accepted: 24 October 2019; Published: 7 November 2019

check for updates

\begin{abstract}
Trichinella spiralis maintains chronic infections within its host, involving a variety of immunomodulatory properties, the mechanisms of which have not been completely elucidated. In this study, we found that $T$. spiralis infection induced strong regulatory $T$ cell responses through parasite excretory-secretory (ES) products, characterized by increase of $\mathrm{CD} 4^{+} \mathrm{CD} 25^{+} \mathrm{Foxp}^{+}$and $\mathrm{CD} 4^{+} \mathrm{CD} 25^{-} \mathrm{Foxp}^{+}$Treg cells accompanied by high levels of IL-10 and TGF- $\beta$. T. spiralis adult worm excretory-secretory products (AES) and muscle larvae excretory-secretory products (MES) were both able to activate BMDCs in vitro to facilitate their maturation and to create regulatory cytokines IL-10 and TGF- $\beta$. The T. spiralis AES- and MES-pulsed dendritic cells (DCs) possessed abilities not only to present antigens to sensitized $\mathrm{CD} 4^{+} \mathrm{T}$ cell to stimulate their proliferation but also to induce naive $\mathrm{CD}^{+} \mathrm{T}$ cells to differentiate to Treg cells secreting IL-10 and TGF- $\beta$. The passive transfer of $T$. spiralis AES- and MES-pulsed bone marrow-derived dendritic cells (BMDCs) conferred the naive mice to acquire the differentiation of Treg cells. T. spiralis AES possesses a better ability to induce Treg cells than did MES, although the latter has the ability to induce $\mathrm{CD} 4^{+} \mathrm{CD} 25^{-}$Foxp $3^{+}$Treg cells. The results obtained in this study suggested that T. spiralis ES products stimulate the differentiation of host Treg cells possibly through activating dendritic cells to create a regulatory environment that benefits the survival of the parasite in the host.
\end{abstract}

Keywords: Trichinella spiralis; excretory-secretory products; $\mathrm{CD} 4^{+} \mathrm{T}$ cell; dendritic cells; regulatory T cells

\section{Introduction}

Parasitic helminths modulate host immune response for long-term survival and continued infection. Through the coordination of complex signaling networks that intimately link the host innate and adaptive immune systems, the host may achieve an efficient immune defense against invading pathogenic microorganisms. Upon interaction with certain antigens presented by dendritic cells (DCs), $\mathrm{CD}^{+} \mathrm{T}$ cells activate, expand, and differentiate into different effector subsets termed Th1, Th2, and Th17 cells and induced regulatory T cells (iTreg). The lymphocyte differentiation is predominantly governed by the cytokines in the microenvironment and, to some extent, by the strength of the interaction of the $\mathrm{T}$ cell receptor with the antigen [1]. For effective control of infections and avoidance of autoimmune and immunopathological diseases, the rigorous regulation of effector $\mathrm{T}$ cell responses is required. As a survival strategy of invading helminthic parasites, chronic helminths 
infection is often associated with polarized Th2 responses and stimulates Treg to produce regulatory and anti-inflammatory cytokines that reduce host immune responses [2]. The iTregs have essential roles in maintaining immune homeostasis by regulating these effector $\mathrm{T}$ cell responses, by facilitating pathogens immune evasion [3], and by preventing potentially pathogenic effects on the host. These effects are achieved through a variety of mechanisms [4-6].

Treg cells have suppressive activity on immune responses, but it had been documented that regulatory $\mathrm{T}$ cell populations remain diverse [7]. Treg cells expressing CD25 and Foxp3 are naturally present in the immune system and considered as negative regulators of immune response. These natural Treg cells originate during thymic development and appear first in fetal circulation [8]. Other cells such as IL-10-secreted Tr1 cells and TGF- $\beta$-secreted certain CD4 ${ }^{+} \mathrm{CD} 25^{-} \mathrm{Foxp}^{+} \mathrm{T}$ cells also have been found to possess regulatory activities [9]. Treg cells with Foxp3 marker are able to suppress the activation, proliferation, and effector functions (such as cytokine production) of natural killer (NK) cells and natural killer $\mathrm{T}(\mathrm{NKT})$ cells, $\mathrm{B}$ cells, $\mathrm{CD} 4^{+}$and $\mathrm{CD} 8^{+} \mathrm{T}$ cells, and antigen-presenting cells (APCs), etc. in vitro and in vivo [10]. Different helminth infections, such as Heligmosomoides polygyrus [11], Schistosoma japonicum [12], Schistosoma mansoni [13], and Brugia malayi [14] are known to provoke an increased number of Foxp3 ${ }^{+}$Tregs.

Trichinella is a fascinating infection model for induction and regulation of differentiation of various $\mathrm{CD} 4^{+} \mathrm{T}$ cells subsets for adaptive immune systems in response to infection. With the infection of T. spiralis, the entire life cycle is completed in the same host where the adult worm, newborn larva (NBL), and muscle larva (ML) are sequentially developed. NBL are released from sexually mature adult worms in the intestine, followed by the migration of NBL to skeletal muscle to develop capsulated infective ML [15]. Each of these life phases may uniquely affect host immune response but have not been adequately investigated to date. Indeed, even in the muscle phase of T. spiralis infection, larvae are "hidden" inside the cysts, which are made of transformed muscle cells called nurse cells surrounded by a collagen capsule [16] and communicated with the host through ML excretory/secretory (ES) products.

As other parasitic helminths, T. spiralis develops a sophisticated strategy to modulate host immune systems to avoid immune attack during the process of the parasite life stage transformation. Such a strategy must be carefully balanced in order to avoid compromising host survival [17]. However, the mechanisms underlying the immunomodulation induced by $T$. spiralis infection has not been completely elucidated. Although we have identified several molecules secreted by T. spiralis playing important roles in the modulation of host immune systems in our previous studies, there is few in vivo data available to support such a cross-regulation among Treg, Th1, Th2, and Th17 responses elicited by T. spiralis infection. These identified molecules include T. spiralis paramyosin (TsPmy) [18-20] and calreticulin [21] expressed on the surface of different stages of T. spiralis as well as in the ES products of adult and muscle larval worms with the ability to bind to their host complement components to avoid host complement attack. It has been also found that TsPmy modulates Treg differentiation to reduce host adaptive immune response as a T. spiralis survival strategy to live in its host [22]. Moreover, T. spiralis adult worm excretory-secretory products (AES) demonstrated a therapeutic potential for alleviating dextran sulfate sodium (DSS)-induced inflammatory colitis in mice with upregulation of Tregs and anti-inflammatory cytokines [23]. However, the mechanism underlying the upregulation of Treg response induced by T. spiralis-secreted products is not clear. In this study, we like to determine whether T. spiralis excretory-secretory products, especially AES, induce the differentiation of regulatory $\mathrm{T}$ cells through activating dendritic cells.

\section{Materials and Methods}

\subsection{Animals}

Specific pathogen-free (SPF) 6-8 week-old female BALB/c mice ( $n=100$ in total), $6-8$ week old female ICR (Institute of Cancer Research) mice ( $n=3$ in total), and female Wistar ( $n=10$ in total) mice with weights of 150-200 g each were purchased from the Laboratory Animal Services Center of the Capital Medical University (Beijing, China). All animal procedures were approved by the 
Capital Medical University Institutional Animal Care and Use Committee (IACUC; Permit Numbers: AEEI-2015-183 and AEEI-2015-184). All mice were maintained under SPF conditions with humidity of $70 \pm 10 \%$ and temperature of $20 \pm 2{ }^{\circ} \mathrm{C}$, and animal protection and care principles were performed in all animals experiments according to the National Institutes of Health (NIH) and IACUC guidelines for the care and use of laboratory animals.

\subsection{Parasites and Antigens Preparation}

T. spiralis (ISS 533 strain) was cultured in female ICR mice, and muscle larvae (ML) were isolated from the muscles of infected ICR mice by a previously described method of modified pepsin-hydrochloric acid digestion [24]. Adult T. spiralis worms were obtained from the intestines of the Wistar mice at $106 \mathrm{~h}$ (4.5 days) after each being orally infected with 12,000 muscle larvae [25]. The excretory-secretory products of T. spiralis ML (MES) and adult worms (AES) were prepared and collected as previously described $[23,26,27]$. T. spiralis ML were freshly collected from mice muscle on day 40 post-infection and washed three times with phosphate-buffered saline (PBS) and then cultured in Roswell Park Memorial Institute (RPMI)-1640 medium (Hyclone, Logan, UT, USA) supplemented with $100 \mathrm{U} / \mathrm{mL}$ penicillin and $100 \mathrm{U} / \mathrm{mL}$ streptomycin (Solarbio, Beijing, China) at $37^{\circ} \mathrm{C}, 5 \% \mathrm{CO}_{2}$ for $48 \mathrm{~h}$. The culture supernatants containing MES products were concentrated by centrifugation and buffer exchanged into PBS and then filtered through a 0.45-micron syringe filter (Merck, Darmstadt, Germany). AES was obtained by culturing adult worms in medium as described for MES collection. The protein concentrations of the prepared T. spiralis ES antigens were determined by bicinchoninic acid (BCA) assay (Merck). The contaminated endotoxin was removed by ToxOut ${ }^{\mathrm{TM}}$ High Capacity Endotoxin Removal Kit (Biovision, San Francisco, CA, USA). All antigens were stored at $-80{ }^{\circ} \mathrm{C}$. Lipopolysaccharide (LPS) (Sigma-Aldrich, St. Louis, MO, USA) was used as a positive control for immune response in vitro.

\subsection{Experimental Infection}

To analyze T cell differentiation and the related-cytokine responses during different stages of T. spiralis infection, each BALB/c mouse was orally infected with 400 infective T. spiralis ML. On day 6, 15,30 , and 60 post-infection, four mice were randomly selected from the infected group and control group and were sacrificed. Spleens were collected, and splenocytes were harvested. Day of collecting was chosen according to the developing stage of the worm in the host. Day 6 was the intestinal phase of T. spiralis; day 15 was newborn larvae migrating in the circulatory system and tissue of host; day 30 was the larva capsule formation phase; and day 60 was the convalescent phase.

\subsection{Cell Culture}

Single cell suspensions of splenocytes were prepared in mouse lymphocyte separation medium according to the manufacturer's instructions (Dakewe Biotech, Shenzhen, China). Subsequently, $2 \times 10^{5}$ /well splenocytes in $200 \mu \mathrm{L}$ of RPMI- 1640 media containing $10 \%$ fetal bovine serum (FBS; Thermo Fisher, Life Technologies, Carlsbad, CA, USA) and $100 \mathrm{U}$ of penicillin/streptomycin/mL were cultured in 96 -well plates at $37^{\circ} \mathrm{C}, 5 \% \mathrm{CO}_{2}$ for $72 \mathrm{~h}$ in the presence of $25 \mathrm{ng} / \mathrm{mL}$ phorbol 12-myristate 13-acetate (PMA; Sigma-Aldrich) and $1 \mathrm{mg} / \mathrm{mL}$ ionomycin (Sigma-Aldrich). Culture supernatants were recovered for detecting different cytokines using corresponding ELISA kits for detecting IL-10, TGF- $\beta$, or IL-21 using the eBioscience ELISA Ready-SET-Go kit (eBioscience, San Diego, CA, USA) and for detecting other cytokines using Mouse ELISA KIT (Dakewe Biotech) according to the manufacturer's instructions.

\subsection{Generation of Bone Marrow-Derived Dendritic Cells (BMDCs)}

Mouse BMDCs were generated from 6 to 8 week-old BALB/c mice according to the procedure described by Ilic et al. [26] with slight modifications. Bone marrow cells were collected from the femur bones of BALB/c mice and passed through a 100- $\mu \mathrm{m}$ Falcon cell strainer (Solarbio) to remove debris and clumps. Red blood cells were lysed using ACK (Ammonium-Chloride-Potassium) lysis buffer (Tiangen, 
Beijing, China). The marrow cell fraction was washed with complete RPMI 1640 medium supplemented with $10 \% \mathrm{FBS}$ and penicillin/streptomycin. Total of $2 \times 10^{6}$ cells was resuspended in $2 \mathrm{~mL}$ complete RPMI 1640 medium in each well of 6-well plates and cultured at $37^{\circ} \mathrm{C}, 5 \% \mathrm{CO}_{2}$ for $3 \mathrm{~h}$. After removing the nonadherent cells, the remaining adherent cells were cultured in RPMI 1640 medium, which contains growth factors of $10 \mathrm{ng} / \mathrm{mL}$ recombinant granulocyte-macrophage colony-stimulating factor (GM-CSF) (Peprotech, Rocky Hill, NJ, USA), 2 ng/mL IL-4 (Peprotech), and 10\% FBS for 6 days with fresh medium change on day 3 and day 5 . The immature BMDCs were harvested for further experiment on day 6.

\subsection{In Vitro BMDCs Activation Assay}

The harvested immature BMDCs generated above were cultivated in 6-well plates in complete RPMI-1640 medium with stimulation of AES $(10 \mu \mathrm{g} / \mathrm{mL})$ or MES $(10 \mu \mathrm{g} / \mathrm{mL})$ at $37{ }^{\circ} \mathrm{C}, 5 \% \mathrm{CO}_{2}$ for $48-72 \mathrm{~h}$. The same cell culture with $2 \mu \mathrm{g} / \mathrm{mL}$ LPS was used as a positive control and with bovine serum albumin (BSA) $(10 \mu \mathrm{g} / \mathrm{mL})$ (Thermo Fisher, Life Technologies) or PBS as a negative control. The stimulated BMDCs were washed and resuspended in $200 \mu \mathrm{L}$ PBS containing $2 \mu \mathrm{L}$ rat anti-mouse CD16/CD32 antibody (BD PharMingen, San Jose, CA, USA) for Fc receptors (FcR) block and then stained with P-phycoerythrin (PE)-labeled anti-mouse CD11c antibodies (BD PharMingen) and fluorescein isothiocyanate (FITC) anti-mouse CD80, CD86, CD40, or MHCII (BD PharMingen) for fluorescence-activated cell sorting (FACS) analysis. The cytokine levels in the BMDCs culture supernatants were determined by corresponding ELISA kits.

\subsection{Co-Incubation of $C D 4^{+} T$ cells with T. spiralis ES-Primed BMDCS}

For evaluation of $\mathrm{T}$ cells proliferation and polarization by T. spiralis ES (TsES)-primed BMDCs, the T. spiralis-sensitized $\mathrm{CD} 4^{+} \mathrm{T}$ cells were collected from the spleens of BALB/c mice infected with T. spiralis using magnetic-activated cell sorting (MACS) with mouse $\mathrm{CD} 4^{+} \mathrm{T}$ cells isolation kits following manufacturer's instructions (Miltenyi Biotec, Bergisch Gladbach, Germany), and naive CD4 ${ }^{+} \mathrm{T}$ cells were isolated from the spleens of naive BALB/c mice by the same protocol as described above. A total of $5 \times 10^{5}$ T. spiralis-sensitized or naive $\mathrm{CD} 4^{+} \mathrm{T}$ cells were co-cultivated with $2.5 \times 10^{4} \mathrm{TsES}$-primed BMDCs in each well of a 96-well plate and labeled with 5- and 6-carboxyfluorescein diacetate succinimidyl ester (CFSE) (eBioscience). In the T. spiralis-sensitized and naive T cell culture, $5 \mu \mathrm{g} / \mathrm{mL}$ anti-CD3 (Peprotech) and $5 \mu \mathrm{g} / \mathrm{mL}$ anti-CD28 (Peprotech) were added as signal one and a costimulatory signal two without leading to early cell death for proliferated cells. For BMDCs/T. spiralis-sensitized T cells co-cultures for $72 \mathrm{~h}$ at $37^{\circ} \mathrm{C}, 5 \% \mathrm{CO}_{2}$, the proliferation of $\mathrm{T}$ cells was measured by fluorescence-activated cell sorting (FACS). The co-incubated BMDCs/naive T cells were continued for $40 \mathrm{~h}$, and cells were recovered for detecting the percentage of $\mathrm{CD} 4^{+} \mathrm{CD} 25^{+} \mathrm{Foxp}^{+} \mathrm{T}$ cells in total $\mathrm{CD} 4^{+} \mathrm{T}$ cells. In addition, in order to determine the cytokine production, the co-incubation supernatants were recovered for measuring cytokine release by ELISA as described above.

\subsection{Adoptive Transfer of TsEs-primed DCs into Naive Mice}

After being incubated with AES or MES $(10 \mu \mathrm{g} / \mathrm{mL})$ in vitro for $48 \mathrm{~h}$, the mouse BMDCs were washed twice in RPMI 1640 and then resuspended in PBS. Each naive BALB/c mouse in a group of 30 mice was injected intravenously with $2 \times 10^{6}$ DCs. The DCs incubated with BSA and PBS were used as nonrelevant protein or negative controls, respectively. One week after the transfer, splenocytes from all the mice were harvested for the analysis of the presence of Tregs and the secretions of the Th1 (IFN- $\gamma$ ), Th2 (IL-4), and Th17 (IL-17) cytokines.

\subsection{TsES-Induced T cells Responses in Mice}

$\mathrm{BALB} / \mathrm{c}$ mice were divided randomly into 3 groups with 4 mice in each group, and each group was immunized intraperitoneally with $200 \mu \mathrm{g}$ AES, $200 \mu \mathrm{g}$ MES, or $200 \mu \mathrm{L}$ PBS twice with 14-day interval. Two weeks after the last immunization, splenocytes from all the mice were harvested for the analysis of cytokine production and the presence of Tregs, Th1, Th2, and Th17 cells. Meanwhile, 
the splenocytes from AES-immunized mice were surface stained with anti-mouse CD3-PerCP-eFluor ${ }^{\circledR}$ 710 (eBioscience) and anti-mouse CD4-FITC (eBioscience). Intracellular staining was done using anti-mouse Foxp3-PE. The $\mathrm{CD} 4^{+} \mathrm{CD} 25^{+} \mathrm{T}$ cells, $\mathrm{CD} 4^{+} \mathrm{CD} 25^{-} \mathrm{T}$ cells, and Foxp3 ${ }^{+} \mathrm{T}$ cells were sorted using the MoFlo XDP cell sorter (Beckman Coulter, Inc, Fullerton, CA, USA).

The $\mathrm{CD} 4^{+} \mathrm{CD} 25^{+} \mathrm{T}$ cells, $\mathrm{CD} 4^{+} \mathrm{CD} 25^{-} \mathrm{T}$ cells, and $\mathrm{CD} 4^{+} \mathrm{Foxp}^{+} \mathrm{T}$ cell samples were stored in Trizol reagent (Life Technologies, Rockville, MD, USA) to extract total RNA. The Treg-related transcription factors and cytokines gene expression were evaluated via real-time PCR.

\subsection{Intracellular Cytokines and Foxp3 Staining}

For FACS analysis of Th1, Th2, or Th17 cells, the harvested splenocytes were stimulated with 25 $\mathrm{ng} / \mathrm{mL}$ PMA, $1 \mu \mathrm{g} / \mathrm{mL}$ ionomycin, and $0.66 \mu \mathrm{L} / \mathrm{mL}$ Golgistop ${ }^{\mathrm{TM}}$ (BD PharMingen) in complete RPMI 1640 medium for $6 \mathrm{~h}$ in 6-well plates at $37^{\circ} \mathrm{C}, 5 \% \mathrm{CO}_{2}$, and then, the harvested cells were FCR blocked with rat anti-mouse $\mathrm{CD} 16 / \mathrm{CD} 32$ antibody and stained as follows: surface stained with anti-mouse CD3-APC-eFluor ${ }^{\circledR} 780$ (eBioscience) and anti-mouse CD4-FITC (eBioscience) and intracellularly stained with anti-mouse IFN- $\gamma$-PE-Cyanine7, anti-mouse IL-4-PE-Cyanine7, or anti-mouse IL-17A-PE-Cyanine7 (or isotype IgG2a, IgG1 control antibody) (eBioscience). Cytofix/Cytoperm buffer was used in the intracellularly staining process (BD PharMingen) for washing, fixing, and permeabilizing cells.

For determination of Tregs, the harvested splenocytes from each mouse were directly FcR antibody blocked and stained with mouse regulatory $\mathrm{T}$ cells staining kit according to manufacturer's instructions (eBioscience). The kit contained stains for antibodies: anti-mouse CD4-FITC, anti-mouse CD25-APC, and anti-mouse Foxp3-PE. The surface marker staining used was PerCp-labeled anti-CD3, FITC-labeled anti-CD4, and APC-labeled anti-CD25. After cells were washed, fixed, and permeabilized, intracellular staining was performed using PE-labeled anti-Foxp3 antibody or IgG2a rat immunoglobulin control antibody. Data were analyzed with Flow software (BD Biosciences, San Jose, CA, USA).

\subsection{Quantitative Real-Time PCR}

The relative changes in expression of Foxp3, TGF- $\beta 1$, and IL-10 genes in CD4 $4^{+} \mathrm{CD} 25^{+}, \mathrm{CD} 4{ }^{+} \mathrm{CD} 25^{-}$, and $\mathrm{CD}^{+} \mathrm{Foxp}^{+} \mathrm{T}$ cells were evaluated via real-time quantitative PCR. Table 1 shows the primer sequences for each detected gene. Total RNA was extracted from $\mathrm{T}$ cells by Trizol reagent method in accordance with the manufacturer's protocols (Life Technologies). After synthesizing cDNA from total RNA using the PrimeScript $1^{\text {st }}$ Strand cDNA Synthesis Kit (Takara, Kusatsu, Japan), real-time quantitative PCR reactions were performed using TransStart Top/Tip Green qPCR SuperMix (TransGen, Beijing, China). The mRNA expression in each sample was finally determined after correction with Hypoxanthine-guanine phosphoribosyltransferase (HPRT) 1 expression. Results were calculated using the $2^{-\Delta \Delta C t}$ method [28]. In brief, the gene-specific threshold cycle (Ct) for each sample $(\Delta \mathrm{Ct})$ was corrected by subtracting the $\Delta \mathrm{Ct}$ for the HPRT 1 housekeeping gene. PBS controls were selected as the reference samples, and the $\Delta \mathrm{Ct}$ for all experimental samples was subtracted from the $\Delta \mathrm{Ct}$ for the control samples $(\Delta \mathrm{Ct})$ :

$$
\Delta \Delta \mathrm{Ct}=\left(\mathrm{CT}_{\text {Target }}-\mathrm{CT}_{\text {Hprt 1 }}\right)_{\text {Time } \mathrm{x}}-\left(\mathrm{CT}_{\text {Target }}-\mathrm{CT}_{\text {Hprt 1 }}\right)_{\text {Time } 0}
$$

where Time $\mathrm{x}$ is any time point and Time 0 represents the $1 \times$ expression of the target gene normalized to HPRT 1.

Table 1. Four pairs of specific primers used for quantitative real-time PCR.

\begin{tabular}{ccc}
\hline Primer & Forward Sequence & Reverse Sequence \\
\hline Foxp3 & $5^{\prime}$-GGCCCTTCTCCAGGACAGA-3' & 5'-GCTGATCATGGCTGGGTTGT-3' $^{\prime}$ \\
TGF- $\beta 1$ & 5'ACCATGCCAACTTCTGTCTG-3' $^{\prime}$ & 5'-CGGGTTGTGTTGGTTGTAGA-3' $^{\prime}$ \\
IL-10 & 5'-CCCTTTGCTATGGTGTCCTT-3' $^{\prime}$ & 5'-TGGTTTCTCTTCCCAAGACC-3' $^{\prime}$ \\
HPRT 1 & 5'-AGCCTAAGATGAGCGCAAGT-3' $^{\prime}$ & 5'-TTACTAGGCAGATGGCCACA-3' $^{\prime}$ \\
\hline
\end{tabular}




\subsection{Statistical Analysis}

All data were presented as means \pm SDs (standard deviations). Statistical significance was calculated with two-tailed $t$-test, one-way analysis of variance (ANOVA), or student's unpaired using the GraphPad Prism version 6 software (San Diego, CA, USA), and $p<0.05$ was considered significant.

\section{Results}

\subsection{T. spiralis Infection Induced Differentiation of Th2 and Treg Cells}

To analyze the effect of $T$. spiralis infection on $\mathrm{CD}^{+} \mathrm{T}$ cells differentiation, the subpopulations of $\mathrm{CD}^{+} \mathrm{T}$ cells isolated from mouse spleens were measured by FACS during different infection stages (Figure 1). The Th2 $\mathrm{CD}^{+}{ }^{+} \mathrm{T}$ cells expressing IL-4 and Treg cells expressing $\mathrm{CD} 4^{+} \mathrm{CD} 25^{+} \mathrm{Foxp}^{+}$and $\mathrm{CD} 4^{+} \mathrm{CD} 25^{-} \mathrm{Foxp}^{+}$were significantly induced at the early intestinal stage ( 6 days post-infection, day 6 , Figure S1) and NBL migration stage (day 15, Figure S1) compared to the those of uninfected mice. The increase of Th1 $\mathrm{CD}^{+}$cells expressing IFN- $\gamma$ was only observed at the early intestinal infection stage (day 6). After adult worms were expelled from intestine and the NBL migrated to muscle to establish encapsulated muscle larvae (days 30-60, Figure S1), all Th1, Th2, and Treg cells were recovered to normal level (no significant difference with uninfected mice). Concurrently, IL-17A ${ }^{+}$Th17 cells were not significantly increased during infection. These results indicated that $T$. spiralis infection mainly induced Th2 and Treg responses during the early infection of T. spiralis and that the maintenance of Th2 and Treg cells must be consistently stimulated by worm infection. After adult worms were expelled from the intestine and muscle larvae were encapsulated, no host cellular immune response was observed.
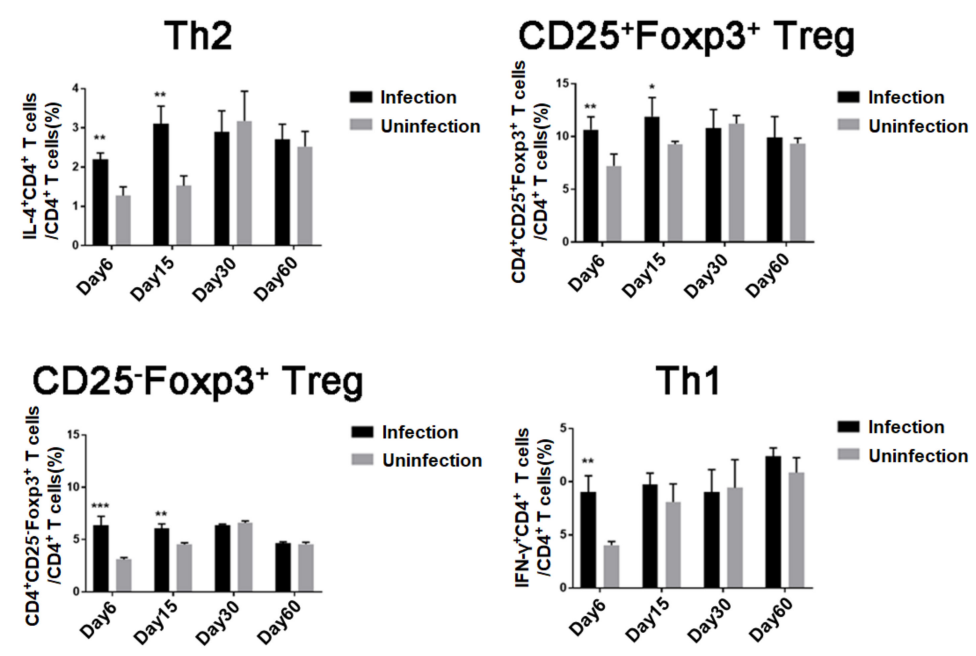

Th17

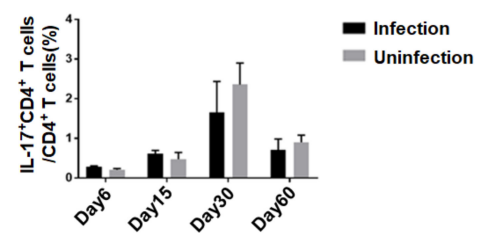

Figure 1. Differentiation of Treg, Th1, Th2, and Th17 cells in mice during T. spiralis infection: For each of three independent experiments, 16 female BALB/c mice were each infected with $400 \mathrm{~T}$. spiralis ML. Four mice were randomly sacrificed at different stages post-infection (intestinal phase, day 6; newborn larva (NBL) migration, day 15; larva capsule, day 30; and convalescent phase, day 60); Th2, Treg, Th1, and Th17 CD4 ${ }^{+} \mathrm{T}$ cells in the spleen were measured by fluorescence-activated cell sorting (FACS). Data are shown as means \pm SDs; ${ }^{*} p<0.05$; ** $p<0.01 ;{ }^{* * *} p<0.001$. 


\subsection{T. spiralis Infection Increased the Expression of Inhibitory Cytokines}

Similar to the cellular differentiation, the cytokine profiles secreted by the splenocytes reflected the induction of Th2 and Treg responses in infected mice. The levels of IL- 4, IL-10, and TGF- $\beta$ were significantly increased in the culture of splenocytes isolated from mice infected with $T$. spiralis during the early stages (days 15-30) compared to the level secreted by the splenocytes of uninfected normal mice. The level of IL-10 remained high during the entire infection period and reached its highest level on day 60. Interestingly, the levels of IL-6, IL-12, and IL-21 were also increased during the early stages of infection and IL-6 and IL-21 reached their highest levels on day 60 . There were no significant increases in the levels of IFN- $\gamma$ and IL-17 during infection. These results indicate that $T$. spiralis infection stimulated regulatory immune responses resulting in increased Treg cells and regulatory cytokines TGF- $\beta$, IL-10, and IL-21 (Figure 2).
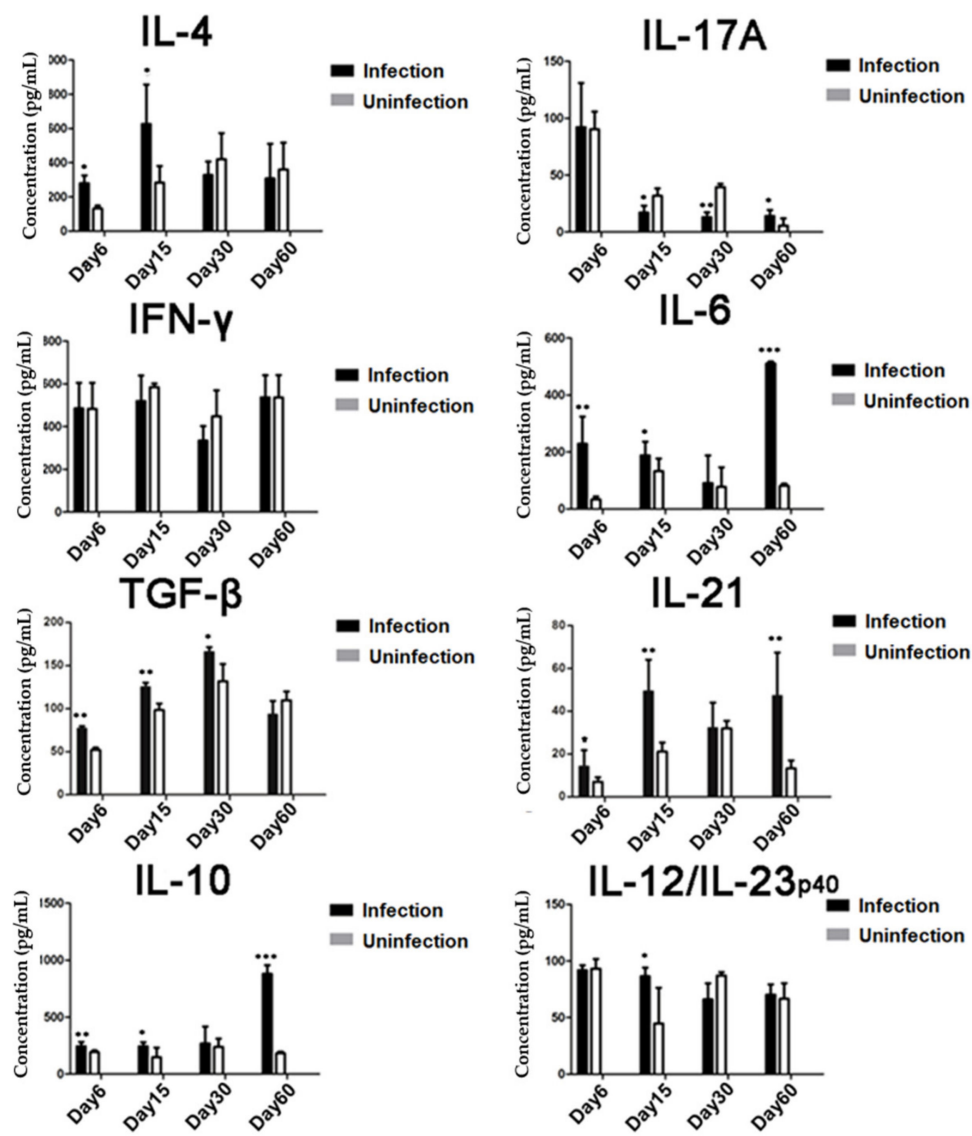

Figure 2. Cytokine profile measured in the culture of splenocytes isolated from T. spiralis-infected mice: On days 6, 15, 30, and 60 after infection with T. spiralis, four infected mice at each time point were sacrificed and splenocytes were isolated. The culture supernatants were collected after being incubated with phorbol 12-myristate 13-acetate (PMA) and ionomycin for $72 \mathrm{~h}$, and the concentrations of IL-4, IL-17A, IFN- $\gamma$, IL-6, TGF- $\beta$, IL-21, IL-10, and IL-12/23p 40 were measured by ELISA. Data are representative of three independent experiments, expressed as means \pm SDs, ${ }^{*} p<0.05 ;{ }^{* *} p<0.01$; *** $p<0.001$, compared to the uninfected group.

\subsection{Immunization with AES or MES Induced Treg Differentiation in Mouse}

To evaluate the role of $T$. spiralis ES products on Treg cell differentiation in vivo, BALB/c mice were immunized intraperitoneally with AES or MES and the $\mathrm{CD} 4^{+} \mathrm{T}$ cells isolated from splenocytes of immunized mice were measured by FACS. Similar to T. spiralis infection, AES immunization significantly increased the percentage of $\mathrm{CD} 4^{+} \mathrm{CD} 25^{+} \mathrm{Foxp}^{+}$and $\mathrm{CD} 4^{+} \mathrm{CD} 25^{-} \mathrm{Foxp}^{+}$Treg cells; however, MES only significantly increased $\mathrm{CD} 4^{+} \mathrm{CD} 25^{-} \mathrm{Foxp}^{+}$Treg cells. Both AES and MES upregulated $\mathrm{CD} 4^{+} \mathrm{T}$ cells 
expressed IFN- $\gamma^{+}$(Th1) and IL-4 ${ }^{+}$(Th2) but not IL-17A ${ }^{+}$(Th17) (Figure 3A). Also as shown in Figure 3A, the cytokine profiles secreted by splenocytes of mice immunized with AES showed high levels of regulatory cytokine IL-10 and TGF- $\beta$, consistent with the increased population of $\mathrm{CD}^{+} \mathrm{CD}^{2} 5^{+} \mathrm{Foxp}^{+}$ Treg cells. The cytokines IFN- $\gamma$ and IL-4 were also highly observed in the supernatant of cell culture of AES-immunized mice. MES immunization only stimulated IL-4 and TGF- $\beta$ (Figure 3B). The findings above confirmed that, similar to the T. spiralis infection, TsES stimulated mixed Th1/Th2 responses along with promoting Treg differentiation, mainly by adult worm excretory-secretory products.

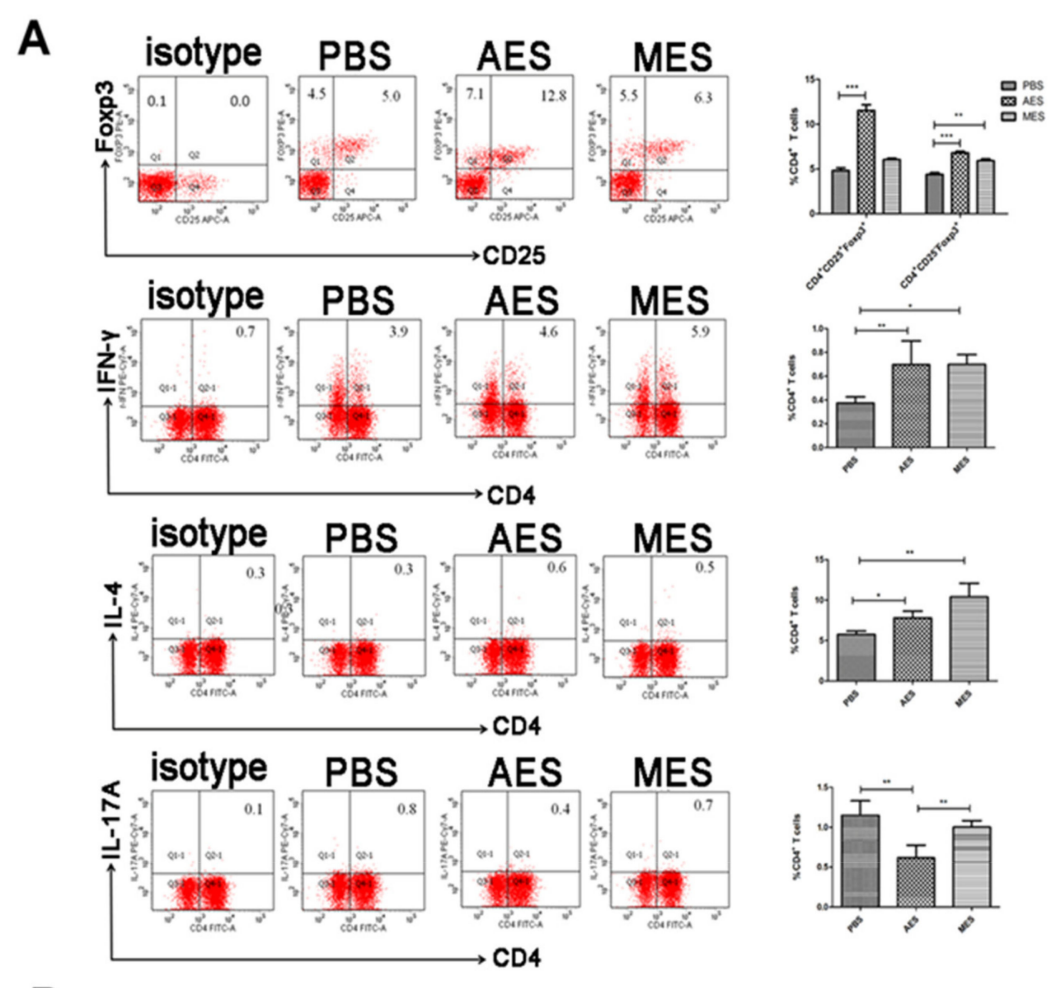

B

IL-10 TGF- $\beta$

IFN- $y$
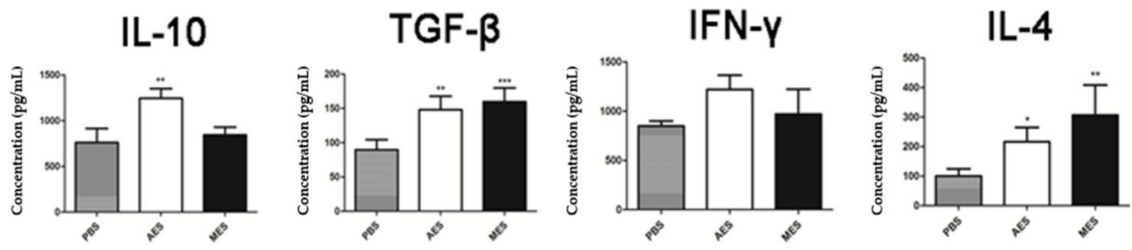

Figure 3. The differentiation of Th1, Th2, Th17, and Treg cells and secreted cytokines in mice immunized with adult worm excretory-secretory products (AES) or muscle larvae excretory-secretory products (MES): (A) The splenocytes were isolated from mice immunized with AES and MES sorted for CD4, CD25, Foxp3 and Th1, Th2, and Th17 by FACS. (B) Splenocyte supernatants were harvested after being cultured $72 \mathrm{~h}$ with PMA/ionomycin, and the cytokine profile in the culture was examined by ELISA. Results are expressed as means \pm SDs from 3 independent experiments. ${ }^{*} p<0.05 ;{ }^{* *} p<0.01$; ${ }^{* * *} p<0.001$, compared to phosphate-buffered saline (PBS) or indicated control.

3.4. The mRNA Expression Profile Further Confirmed that AES Immunization Upregulated the Expressions of Foxp3, TGF- $\beta$, and IL-10

As $\mathrm{CD}^{+}{ }^{+} \mathrm{Foxp}^{+} \mathrm{T}$ cells have different $\mathrm{CD} 25$ expressions, effects of AES or MES on the mRNA expression of transcription factors and cytokines in $\mathrm{CD} 4{ }^{+} \mathrm{CD} 25^{+}$and $\mathrm{CD} 4^{+} \mathrm{CD} 25^{-} \mathrm{T}$ cells from BALB/c mice spleens in vivo were examined. The expression level with Foxp3, a master transcription factor for the development and function of regulatory T cells, was upregulated for T. spiralis ES groups. Comparing the PBS group with the higher expression in the AES group, the evidence shows AES preferentially induces Foxp3 ${ }^{+}$Treg cells to likely produce higher levels of TGF- $\beta$ and IL-10, which 
are the anti-inflammatory cytokines produced by Treg that play important roles in host defense. The mRNA expressions of TGF- $\beta$ and IL-10 were elevated with T. spiralis ES immunization. AES mainly induced Foxp3+ and TGF- $\beta$, and MES mainly induced IL-10 (Figure 4). The results indicated that functional Tregs were induced better by AES than by MES (Figure 4A). Further experiments with AES confirmed that AES significantly induced the expressions of Foxp $3^{+}$, IL-10, and TGF- $\beta$ mRNA in $\mathrm{CD}^{+} \mathrm{Foxp}^{+} \mathrm{T}$ cells (Figure 4B). Together, these findings support a conclusion that TsESs, especially AES, upregulate the differentiation of Treg cells and the secretion of regulatory cytokines IL-10 and TGF- $\beta$ in both protein and mRNA expression levels.
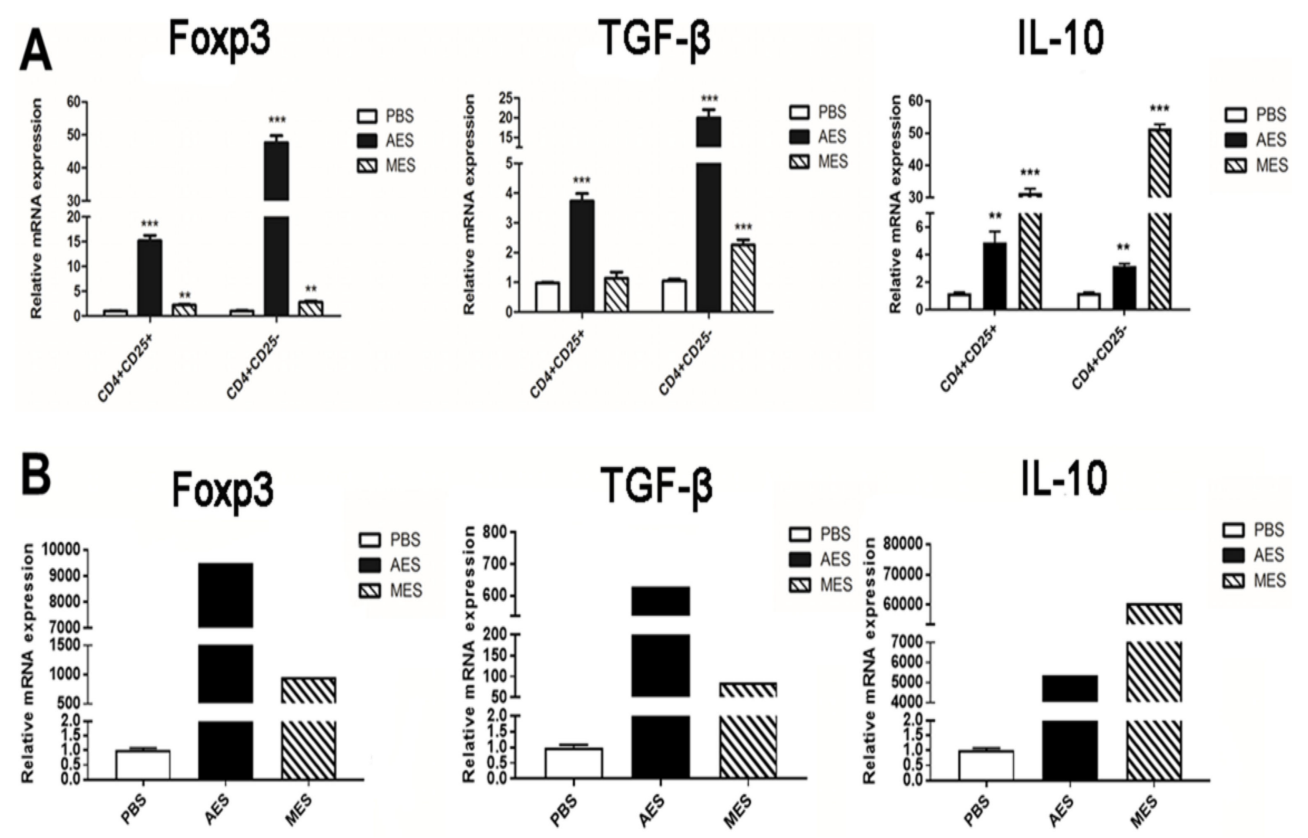

Figure 4. mRNA expression profile for Treg-related marker proteins in mice immunized with AES and MES: BALB/c mice were immunized with AES, MES, or PBS. (A) The CD4 ${ }^{+} \mathrm{CD} 25^{+}$and $\mathrm{CD} 4^{+} \mathrm{CD} 25^{-} \mathrm{T}$ cells were acquired by FACS, and the mRNA for Foxp $3^{+}$, TGF- $\beta$, and IL-10 was measured by RT-PCR. (B) $\mathrm{CD}^{+} \mathrm{Foxp}^{+} \mathrm{T}$ cells were isolated by FACS for mRNA analysis of Foxp3, IL-10, and TGF- $\beta$. Results are presented as means \pm SDs from three independent experiments normalized to the level of HPRT 1. ${ }^{* *} p<0.01 ;{ }^{* * *} p<0.001$, compared to the PBS control.

\subsection{T. spiralis ES Induces Maturation of BMDCs}

To investigate whether T. spiralis ES induces the maturation of DCs, the mouse BMDCs were stimulated with T. spiralis ES antigens for $48 \mathrm{~h}$ and surface markers for DC maturation were examined by FACS. We found that AES and MES of $T$. spiralis significantly upregulated the expressions of CD40, CD80, CD86, and MHC II on CD11 ${ }^{+}$DCs, as did the positive control LPS, when compared to PBS control (Figure 5A). As a nonrelevant protein control, BSA had no effect on the maturation of DCs. These data indicate that T. spiralis-secreted AES or MES were able to induce the maturation of mouse BMDCs. The cytokine profile secreted by treated BMDCs demonstrated that both AES and MES significantly stimulated the secretion of regulatory cytokines IL-10 and TGF- $\beta$ and of cytokine IL-12/23p40. MES also stimulated some other Th1/Th2 cytokines such as IL-1 $\beta$, IL-4, IL-5, IL-6, INF- $\gamma$, and TNF- $\alpha$. (Figure 5B). These results indicated that stimulation with T. spiralis AES and MES activated DCs to create a microenvironment of regulatory factors (IL-10 and TGF- $\beta$ ) which may benefit Treg cell induction. 
A

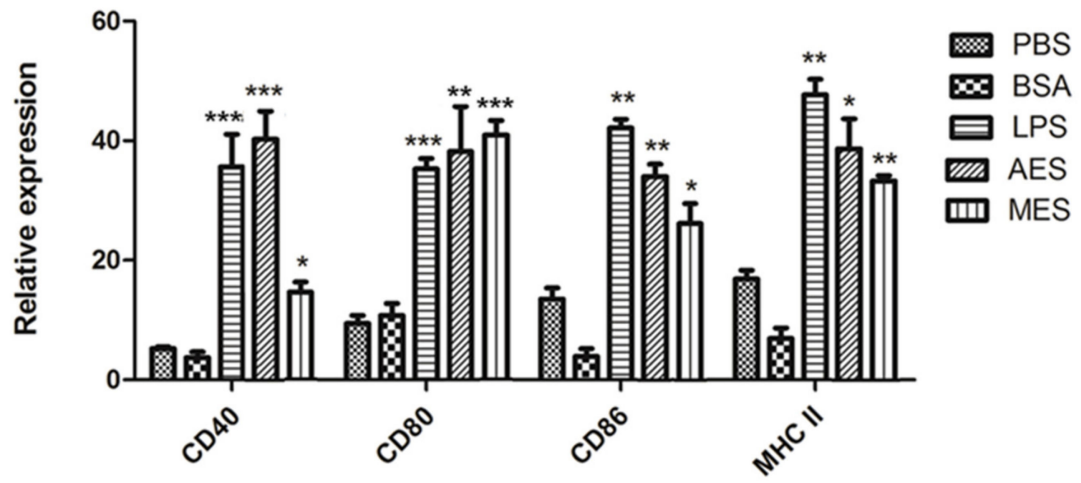

\section{B}
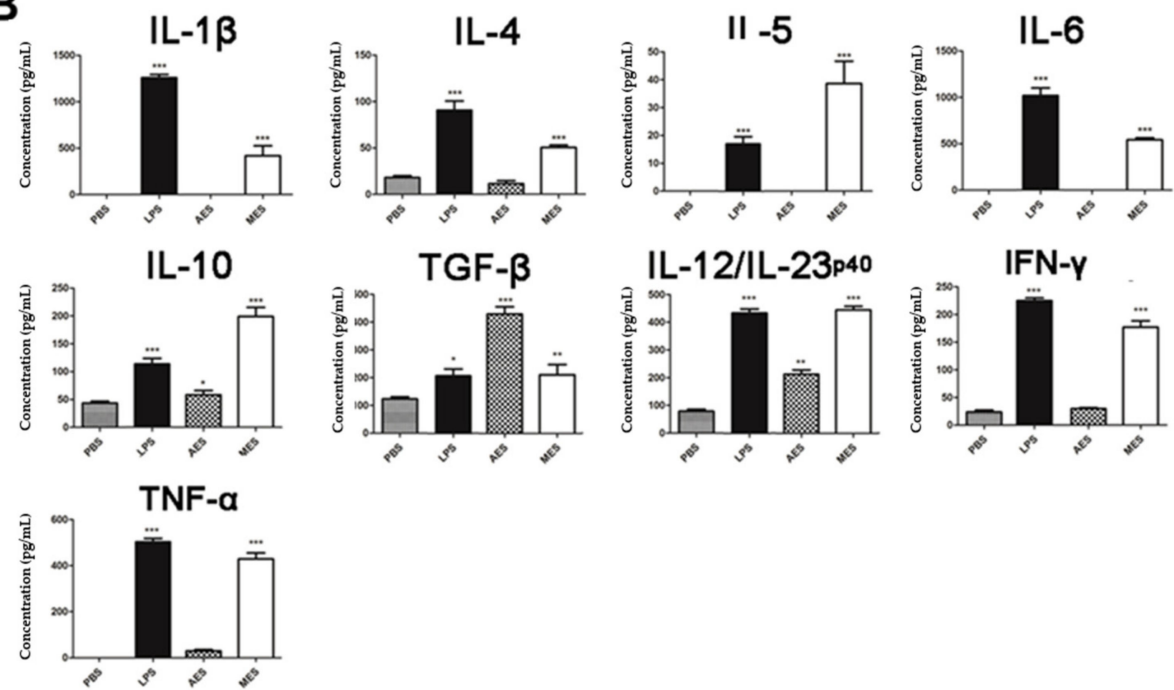

Figure 5. Maturation of Bone Marrow-Derived Dendritic Cells (BMDCs) pulsed by T. spiralis excretory/secretory (ES) products: Mouse BMDCs were cultured for $48 \mathrm{~h}$ with PBS, BSA, lipopolysaccharide (LPS), MES, or AES. (A) Surface markers (CD40, CD80, CD86, and MHC II) on DCs were sorted by FACS and the percentage of surface markers expression on CD11 ${ }^{+}$DCs stimulated with the indicated antigens. (B) Cytokines secreted by T. spiralis ES-stimulated BMDCs in the culture supernatant were measured by ELISA. Results are presented as means \pm SDs from three individual experiments. ${ }^{*} p<0.05$; ${ }^{* *} p<0.01 ;{ }^{* * *} p<0.001$, compared to the PBS group.

\subsection{TsES-Pulsed BMDCs Presents Antigens to T Cells}

To assess whether TsES-stimulated BMDCs have the ability to present antigens to memory T cells, T. spiralis-sensitized $\mathrm{CD}^{+} \mathrm{T}$ cells were acquired from spleens of mice infected with $T$. spiralis and then co-cultured with AES- or MES-stimulated DCs for $72 \mathrm{~h}$ in the presence of anti-CD3/anti-CD28. Results demonstrated that $T$. spiralis-sensitized $\mathrm{CD}^{+} \mathrm{T}$ cells were highly proliferated when incubated with BMDCs primed with AES or MES but not with BMDCs incubated with PBS only. The results indicate that TsES-primed BMDCs enable to present T. spiralis antigens in AES and MES to memory $\mathrm{CD}^{+} \mathrm{T}$ cells that have been sensitized by T. spiralis infection (Figure 6A,B). Concurrently, the memory response of $T$. spiralis-sensitized $\mathrm{CD} 4^{+} \mathrm{T}$ cells to the antigen presented from primed BMDCs produced high levels of IL-4, IFN- $\gamma$, TGF- $\beta$, and IL-10 (Figure 6 C), indicating that the antigen presentation induced mixed Th1/Th2/Treg responses in sensitized CD4 ${ }^{+} \mathrm{T}$ cells. LPS-stimulated BMDCs only induced IFN- $\gamma$ production. The results of proliferation and cytokine profiling clearly showed that T. spiralis-activated DCs enabled to present antigens to sensitized $\mathrm{T}$ cells to induce memory activation, with mixed Th1/Th2/Treg responses. 
A

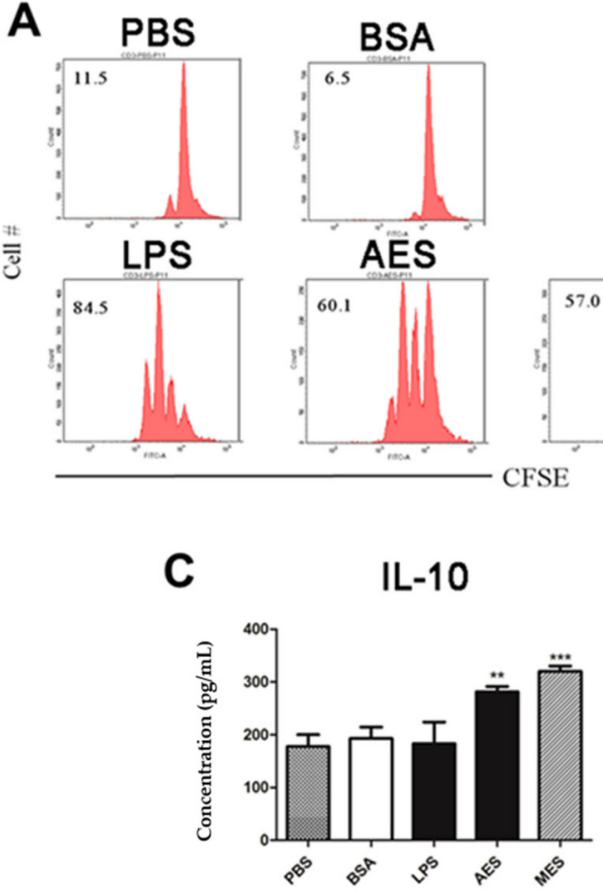

IFN-Y

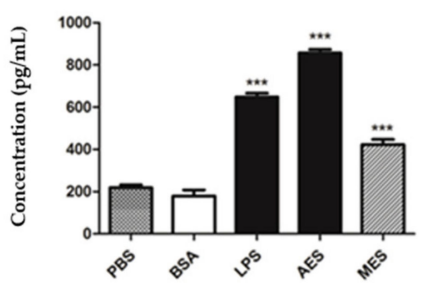

B

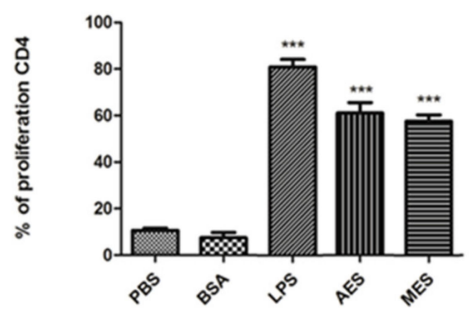

TGF- $\beta$

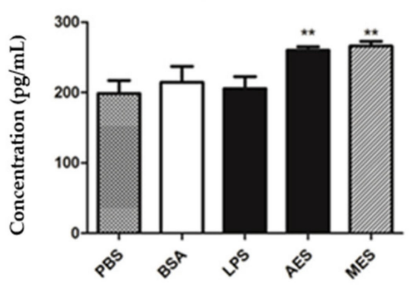

IL-4

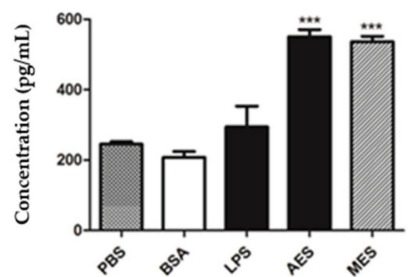

Figure 6. Proliferation and cytokines production of T cells in response to T. spiralis ES (TsES)-treated DCs: CD4 ${ }^{+} \mathrm{T}$ cells were isolated from splenocytes of $T$. spiralis-infected BALB/c mice, labeled with CFSE, and co-cultured for $72 \mathrm{~h}$ with BMDCs (stimulated with PBS, BSA, LPS, AES, or MES) in the presence of anti-CD3/anti-CD28. (A,B) FACS of T cells proliferation from one experiment of three independent experiments is presented. (C) Cytokine levels were measured in cell culture supernatants using ELISA. Data are expressed as means \pm SDs from three independent experiments. Each experiment was done in triplicates. ${ }^{* *} p<0.01 ;{ }^{* * *} p<0.001$, compared to the PBS control.

\subsection{TsES-Primed DCs Induced Treg Cells In Vitro}

In order to evaluate whether T. spiralis ES antigens could induce Treg cells in vitro, the population of $\mathrm{CD}^{+} \mathrm{CD} 25^{+} \mathrm{Foxp}^{+} \mathrm{T}$ cells was measured in $\mathrm{CD} 4+\mathrm{T}$ cells of naive BALB/c mice after being cultivated with AES- or MES-primed BMDCs. We found that AES- and MES-primed BMDCs significantly increased the percentage of $\mathrm{CD} 4{ }^{+} \mathrm{CD} 25^{+} \mathrm{Foxp}^{+} \mathrm{T}$ cells compared to the BMDCs incubated with PBS or BSA only (Figure 7A,B). LPS also elevated the proportion of $\mathrm{CD} 4^{+} \mathrm{CD} 25^{+} \mathrm{Foxp} 3^{+} \mathrm{T}$ cells, possibly associated with LPS-induced tolerogenic BMDCs. Cytokines profiles of co-cultured supernatants also demonstrated increased IL-10 and TGF- $\beta$ of regulatory cytokines, as well as IL-4, IFN- $\gamma$, and IL-17A (Figure 7C). 
A

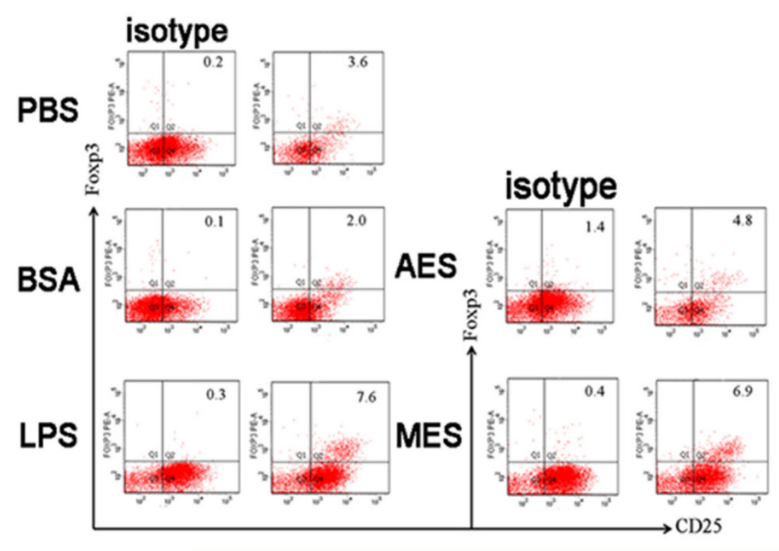

c

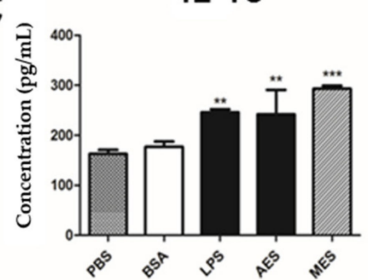

IFN-y

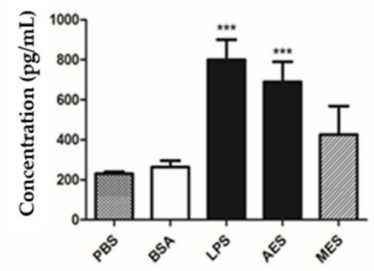

B

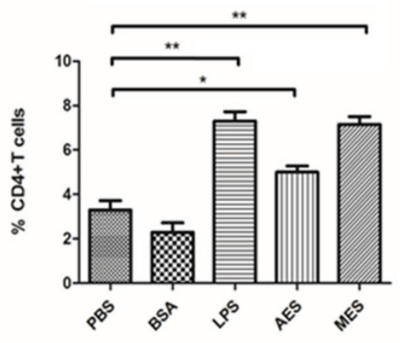

TGF- $\beta$

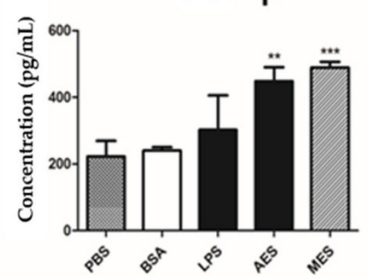

IL-4

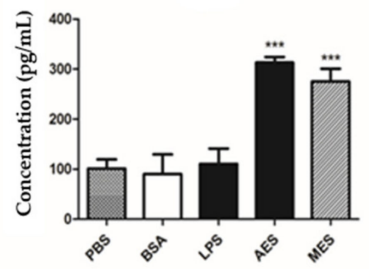

Figure 7. TsES-primed BMDCs upregulated Foxp $3^{+} \mathrm{CD} 4^{+} \mathrm{CD} 25^{+} \mathrm{T}$ cells populations and Treg cytokines in naive T cells. T cells were isolated from naive BALB/c mice splenocytes and co-cultured with AES-, MES-, LPS-, BSA-, or PBS-treated BMDCs in the presence of anti-CD3/anti-CD28 for $48 \mathrm{~h}$. (A) The cells were sorted with CD3, CD4, CD25, and Foxp3 by FACS. (B) Percentage of CD25 $5^{+}$Foxp3 ${ }^{+}$cells in a $\mathrm{CD}^{+} \mathrm{T}$ cell population is shown. (C) Cytokines in co-cultured supernatants were detected by ELISA. Data are shown as the means \pm SDs for three independent experiments. Results represent one of three independent experiments. ${ }^{*} p<0.05 ;{ }^{* *} p<0.01$; ${ }^{* * *} p<0.001$, compared to PBS or BSA control.

\subsection{TsAES-Pulsed DCs Upregulated Treg Cells In Vivo}

To determine whether TsES-pulsed DCs could drive the differentiation of $\mathrm{CD} 4{ }^{+} \mathrm{CD} 25^{+} \mathrm{Foxp} 3^{+}$ $\mathrm{T}$ cells in vivo, TsES-primed DCs were passively transferred into naive mice. The levels of $\mathrm{CD} 4{ }^{+} \mathrm{CD} 25^{+} \mathrm{Foxp}^{+}$Tregs in the spleen of those mice passively transferred with TsAES-pulsed DCs were significantly elevated compared to those that received PBS or BSA-pulsed BMDCs, while $\mathrm{CD} 4^{+} \mathrm{CD} 25^{+} \mathrm{Foxp}^{+}$Treg populations did not change in mice who received TsMES-pulsed DCs (Figure 8A,B), even though TsMES-pulsed DCs induced significantly higher CD4 ${ }^{+} \mathrm{CD} 25^{-} \mathrm{Foxp} 3^{+}$Treg $(p<0.01)$ compared to the PBS control. Passive transfer of both TsMES- and TsAES-pulsed BMDCs induced high levels of IL-4 and IL-17A but not INF- $\gamma$, compared to the level of mice that received PBS-treated BMDCs (Figure 8C-F). The results suggest that helminth excretory-secretory products upregulate $\mathrm{CD}^{+} \mathrm{CD}^{2} 5^{+} \mathrm{Foxp}^{+}$Treg and Th2 polarization possibly through programming DCs. 

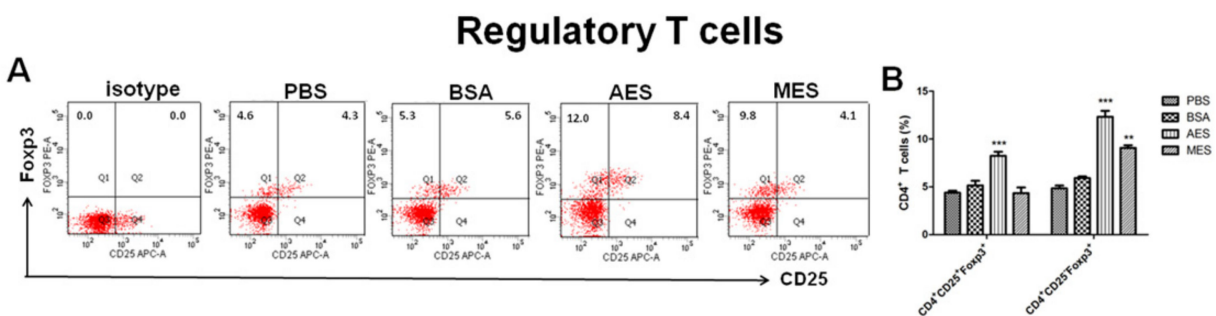

Intracellular cytokines
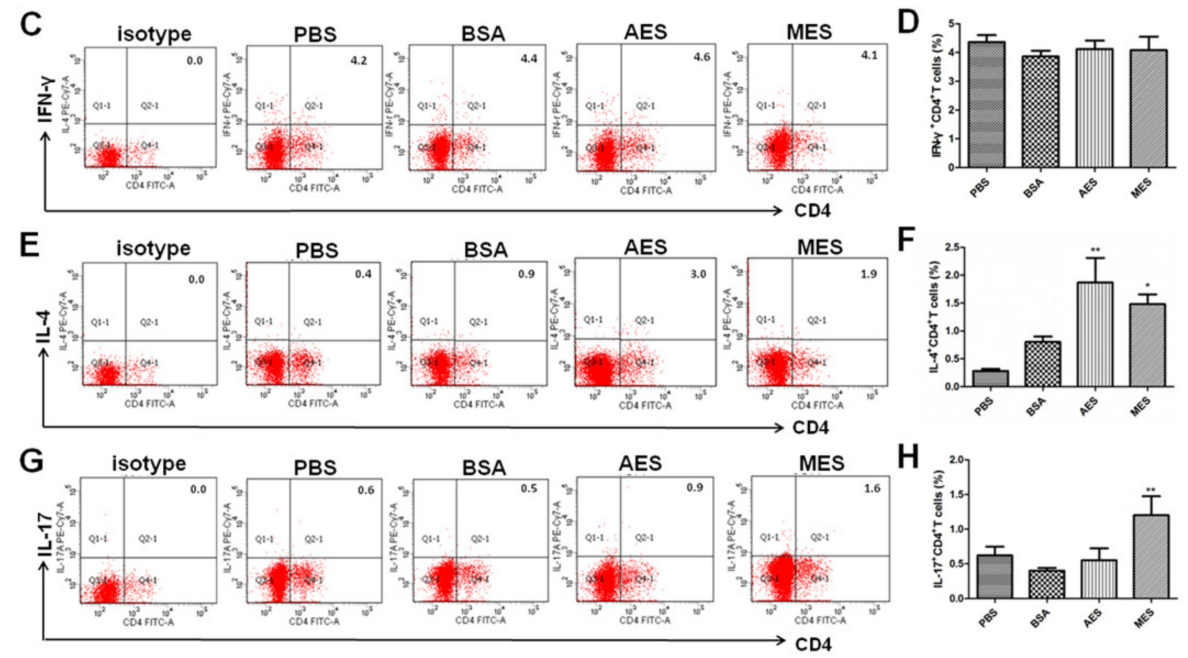

Figure 8. TsES-pulsed DCs induced Treg cell differentiation and Th2 cytokine in naive CD4 ${ }^{+} \mathrm{T}$ cells in vivo. The splenocytes were isolated from naive BABL/c mice passively transferred with TsAES-, TsMES-, PBS-, and BSA-treated BMDCs. (A) The frequencies of $\mathrm{CD} 4^{+} \mathrm{CD} 25^{+} \mathrm{Foxp}^{+}$ and $\mathrm{CD} 4^{+} \mathrm{CD} 25^{-}{ }^{-}{ }^{2}{ }^{-} 3^{+} \mathrm{T}$ cells were measured by gated flow cytometry. (B) The percentages of $\mathrm{CD}^{+} \mathrm{CD} 25^{+} \mathrm{Foxp}^{+}{ }^{+} \mathrm{T}$ cells and $\mathrm{CD} 4^{+} \mathrm{CD} 25^{-} \mathrm{Foxp}^{+} \mathrm{T}$ cells are presented as the mean $\pm \mathrm{SEM}$ of five individual mice per group. $(\mathbf{C}, \mathbf{D})$ Frequencies of $\mathrm{CD} 4^{+} \mathrm{T}$ cells producing IFN- $\gamma^{+},(\mathbf{E}, \mathbf{F})$ frequencies of $\mathrm{CD}^{+} \mathrm{T}$ cells producing $\mathrm{IL}-4^{+}$, and $(\mathrm{G}, \mathrm{H})$ frequencies of $\mathrm{CD} 4^{+} \mathrm{T}$ cells producing $\mathrm{IL}-17 \mathrm{~A}^{+}$are shown. The data are presented as the mean \pm SEM of three independent experiments. ${ }^{*} p<0.05 ;{ }^{* *} p<0.01$; ${ }^{* * *} p<0.001$ in a one-way analysis of variance followed by Bonferroni correction.

\section{Discussion}

In this study, we have identified that $T$. spiralis infection induced the generation of both $\mathrm{CD}^{+} \mathrm{CD} 25^{+} \mathrm{Foxp}^{+}$and $\mathrm{CD} 4^{+} \mathrm{CD} 25^{-} \mathrm{Foxp}^{+}$Treg cells in the early infection stages including the intestinal phase and the NBL migration phase, associated with high levels of regulatory cytokines IL-10, TGF- $\beta$, and IL-21. The results are consistent with other helminth infections that stimulated Foxp3 ${ }^{+}$ Treg cells. Long-term persistence of $H$. polygyrus infection was associated with enhanced frequencies of Treg cells and associated with IL-10 and TGF- $\beta$ production [11]. Both B. malayi larvae and adults induced Treg cells accompanied by raised CTLA-4, CD25, and CD103 expression [14]. Likewise, filarial helminth Litomosoides sigmodontis infection induced hyporesponsiveness that can be reversed by depletion of Treg cells in mice [29]. Treg cells and regulatory cytokines IL-10 and TGF- $\beta$ participated in immune evasion of helminth infection by negative regulation of the host immune system.

In addition, T. spiralis infection is characterized by induction of Th1 and Th2 response in the intestinal phase in which $T$. spiralis rapidly develops to adult worms. The mature adult worms produce newborn larvae, which disseminate through blood circulation to the muscles. The larvae migration stimulates strong Th2 response that results in the expulsion of adult worms and NBL from the intestine [2,30]. In this study, we confirmed that the intestinal phase of $T$. spiralis induced mixed Th1/Th2 responses as reflected by the increased CD4 ${ }^{+}$T cells that expressed IFN- $\gamma$ (Th1) and IL-4 (Th2) as well as increased levels of IFN- $\gamma$ and IL-4. When the larvae migrated to muscle, we observed the 
predominant Th2 response with high levels of IL-4- and IL-4-expressed CD4 ${ }^{+}$cells. After larvae moved to muscle and ML, all Th1/Th2/Treg responses returned to normal, possibly due to encapsulation and isolation of ML from host immune systems. In our study, we observed the slight increase of Th17 response at the early infections of the intestinal adult stage and the larval migration stage, and it is correlated with Th2 responses and worm expulsion. The results are consistent with the observation that DC-activated TGF- $\beta$ induced Th17 to stimulate the intestinal contractility and the expulsion of T. spiralis worms [31], and then, Th17 returned to normal or even decreased at the late stage of infection. It is possible that early T. spiralis infection induces the Th2 and Th17 responses that result in the expulsion of adult worms from intestines. The increased TGF- $\beta$ may contribute to the early increase of Th17 and may strongly contribute to the stimulation of Treg that inhibits inflammation and benefits worm's survival. The reciprocal development of Th17 and Treg responses during infection is important for the balance of immune protection and immunopathology [32]. TGF- $\beta$ was also involved in the control of local inflammation in infected muscle and promotes parasite survival [33]. The results showed that T. spiralis infection induced the differentiation of Treg cells that may play an immunomodulatory role and inhibits inflammatory response for parasite persistence in hosts during T. spiralis infection.

As multicellular pathogens, helminth induce and regulate host immune responses through their exposed antigens recognized by the host immune system. Parasitic helminth ES proteins are the major components of antigens that stimulate host immune responses [26]. ES products from different stages of T. spiralis regulated host immune responses at the macrophage level in vitro by inhibiting pro-inflammatory cytokine production, by boosting the expression of anti-inflammatory cytokines IL-10 and TGF- $\beta$, and by inducing macrophages toward the alternative phenotype, all of which may play important roles in the worm survival in the host and protect hosts from unnecessary damage caused by excessive inflammatory responses [34].

DCs are highly specialized antigen-presenting cells that are important not only in initiating immune responses but also in regulating the magnitude and differentiation of the immune responses [35]. For infection, pathogens and/or their products may interact with DCs through various families of pattern recognition receptors, such as Toll-like receptors [36,37], facilitating DC maturation which is the basis for the generation and polarization of the adaptive immune responses. Different helminth-derived molecules from one particular helminth or from different developmental stages of worms, are able to induce either full or incomplete maturation of DCs and subsequent induction of Th2 and/or regulatory responses [38-40]. In this study, we identified that incubation of ES products from adult T. spiralis (AES) and from ML (MES) with mouse BMDCs strongly inducing the expressions of CD40, CD80, CD86, and MHCII on the surface of CD11 ${ }^{+}$BMDCs, indicating the BMDCs were primed by the TsES to the status of full maturation. The cytokine profile secreted by the primed DCs showed that AES mainly induced IL-10, TGF- $\beta$, and IL-12/23p 40 . IL-10 and TGF- $\beta$ are the major regulatory cytokines. IL-12/23p40 plays a critical role in differentiating Th1 and in stabilizing the Th17 phenotype [41]. However, MES-stimulated DCs secreted a variety of Th1/Th2/Treg cytokines such as IL-1 $\beta$, IL-4, IL-5, IL-6, IL-10, IL-12/23p40, TGF- $\beta$, IFN- $\gamma$, and TNF- $\alpha$. The results indicate that both AES and MES not only induce the maturation of DCs but also induce them to secrete high levels of regulatory cytokines IL-10 and TGF- $\beta$ in addition to other Th1/Th2 cytokines. No significant increase of IL-12 in DCs stimulated using MES antigens was observed by Ilic N. et al. [42]. The possible reason for the different level of IL-12 stimulation compared to Ilic's results is the different DCs. We used mouse BMDCs while Ilic used human peripheral blood mononuclear cell (PBMC)-derived DCs. AES- and MES-pulsed DCs can create a microenvironment of regulatory cytokines that may stimulate the differentiation of Treg cells. It is consistent with other studies that showed T. spiralis-produced antigens induced the full maturation of DCs $[43,44]$. A recent study reported that GM-CSF-derived BMDCs may contaminate monocyte-derived macrophages in addition to the conventional CD11 $\mathrm{c}^{+} \mathrm{MHCII}{ }^{+} \mathrm{DCs}$ [45]. We cannot exclude the possible contamination of macrophages in our culture study; however, the highly increased expressions of $\mathrm{CD} 40, \mathrm{CD} 80$, and $\mathrm{CD} 86$ on $\mathrm{CD} 11 \mathrm{c}^{+} \mathrm{MHCII}^{+}$cells, indicating at least the DC portion in 
the complex, were stimulated by T. spiralis ES products. However, further in vivo activation of DCs by T. spiralis infection or worm-derived ES products is needed to confirm the conclusion.

To investigate whether TsES-pulsed DCs have the ability to process and present antigens to help $\mathrm{T}$ cells, the sensitized $\mathrm{CD} 4^{+} \mathrm{T}$ cells collected from $T$. spiralis-infected mouse were co-cultured with AES or MES-pulsed BMDCs. Results showed that the T. spiralis-infected mouse CD4 ${ }^{+} \mathrm{T}$ cells were highly proliferated, accompanied by the secretion of cytokines IL-10, TGF- $\beta$, IFN- $\gamma$, and IL- 4 , thus confirming that both AES- and MES-activated DCs have the ability of antigen presentation. DCs can modulate immune responses through diversified mechanisms, for example, production of cytokines, suppression of pro-inflammatory mediators, expression of costimulatory molecules, and especially polarization of Tregs $[46,47]$. Stimuli are responsible for this polarization via DCs. In order to determine whether AES and MES possess the immunomodulatory ability to induce Treg differentiation through DCs so as to stimulate the host T cells regulatory network, the AES or MES was used to pulse DCs and the AES- or MES-pulsed DCs were co-incubated with naive $\mathrm{CD} 4^{+} \mathrm{T}$ cells. As the results with immunization of AES or MES in vivo, the AES- and MES-pulsed DCs were also enabled to induce $\mathrm{CD}^{+}{ }^{+} \mathrm{CD} 25^{+} \mathrm{Foxp}^{+}$Treg cells in vitro, accompanied by higher levels of IL-10 and TGF- $\beta$, which are mostly secreted by Tregs [48], indicating that AES- or MES-pulsed DCs can modulate host immune responses with differentiation of Tregs, possibly by creating a regulatory cytokine microenvironment or by presenting T. spiralis excretory-secreted antigens to $\mathrm{CD} 4^{+} \mathrm{T}$ cells. Interestingly, we observed that the AES upregulated TGF- $\beta$ expression to a greater extent than MES did, whereas MES had greater influence on enhancing IL-10 than AES did. It is possible that IL-10 and TGF- $\beta$ are stimulated by different components in the ES products that cause the different levels of both regulatory cytokines when stimulated by AES and MES. However, it seems that TGF- $\beta$ contributes more stimulation to Treg [32] than IL-10 does in this study.

Although it was confirmed that T. spiralis ES antigens possessed the ability to immunomodulate host immune responses by upregulating Treg cells, the ES products from adult worms or ML have different abilities to simulate different Treg cells. Immunization with AES induced both $\mathrm{CD} 4^{+} \mathrm{CD} 25^{+} \mathrm{Foxp} 3^{+}$ Tregs and $\mathrm{CD} 4^{+} \mathrm{CD} 25^{-}$Foxp $3^{+}$Tregs associated with higher level of TGF- $\beta$, but MES mainly induced $\mathrm{CD} 4^{+} \mathrm{CD} 25^{-} \mathrm{Foxp}^{+}$Tregs associated with higher levels of IL-10 and IL-5. It has been confirmed that Foxp3 expression rather than CD25 is essential for Treg suppressive activity [49]. However, $\mathrm{CD} 4{ }^{+} \mathrm{CD} 25^{-}$effector $\mathrm{T}$ cells have better restriction to inflammation than $\mathrm{CD} 4^{+} \mathrm{CD} 25^{+} \mathrm{T}$ cells during T. spiralis chronic infection [33]. The specific stimulation of CD4 ${ }^{+} \mathrm{CD} 25^{-}$Foxp $3^{+}$Treg cells with ES probably suggests that $T$. spiralis ES antigens may be involved not only in the Treg differentiation but also in the control of inflammation during T. spiralis chronic infection. The different levels of different types of Tregs and cytokines may result from the different components of ES secreted by the different stages of the nematode. At the adult stage, as a strategy of survival, the parasite secreted more immunomodulatory products that induced a higher level of Tregs to reduce the immune attack to the adult parasite in the intestine. When the larvae migrate to muscle to form larval capsules, it may not be so important to induce the regulatory inhibition to escape from host immune attack because the larvae acquire the protection by the isolation of capsules in muscle.

The TsES-induced host Treg differentiation possibly through activating DCs was also confirmed by the passive transfer of AES- or MES-pulsed BMDCs to naive mice. The recipient naive mice acquired strong Treg response and Th2 response, indicating that T. spiralis ES products stimulate Treg cell differentiation and Th2 polarization possibly through programming DCs. Our results are consistent with other studies for mice passively transferred with T. spiralis antigen-activated DCs that induced immunomodulatory effects to reduce inflammatory encephalomyelitis [50]. T. spiralis ES products were also used to alleviate DSS-induced colitis by inducing Treg expressing IL-10 and TGF- $\beta$.

Additionally, mice immunized with AES also induced significantly increases of Th1 and Th2 cells, consistent with characteristics of T. spiralis infection in the intestinal phase. AES caused slight inhibition of Th17 response, probably resulting from the induction of Foxp ${ }^{+}$Tregs. Unlike infection of ML phase that did not show Th1 response, MES induced both Th1 and Th2 responses during immunization, 
possibly because ML was hidden within the capsule structure that reduce MES from exposure to host immune system.

Even though we provided some evidences in this study showing that T. spiralis-produced ES products, especially AES, induced differentiation of regulatory $\mathrm{T}$ cell response through activating DCs in vitro, there are still a lot that are not clear and need to be further explored, for example, whether the regulatory effects of AES on DCs identified in vitro could be confirmed in vivo; what are the detail receptors on DCs that AES activate and the following pathways that lead to the regulatory property? What are the specific components in the ES products that are involved in the regulatory activation of DCs and other immune cells? These questions are listed on our agenda to be investigated. We believe parasitic helminths secrete some molecules, including proteins, peptidoglycans, or glycolipids that modulate and reduce host immune response, including the activation of regulatory DCs, as a survival strategy. Actually, some proteins have already been discovered to be involved in the regulatory property during T. spiralis infection. One of these proteins is T. spiralis-secreted paramyosin (TsPmy) [51]. It has been identified that TsPmy modulates host immune response not only by binding to host complement component to reduce complement-involved immune attack [20] but also by activating the regulatory property of DC to stimulate Treg response [22]. The recombinant TsPmy protein was able to induce the differentiation of Treg cells by activating mouse bone marrow-derived DCs, similar to the results we found in AES in this study. However, the interaction between helminth and host, especially the immunomodulatory effects, should be mediated by a complex of molecules secreted by parasitic helminth; TsPmy may be just one of them involved in this function. More efforts are being paid to identify other molecules playing this role as targets for vaccine development.

\section{Conclusions}

In conclusion, as part of survival strategy, T. spiralis infection induces strong host regulatory $\mathrm{T}$ cell responses characterized by increasing $\mathrm{CD} 4^{+} \mathrm{CD} 25^{+} \mathrm{Foxp}^{+}$and $\mathrm{CD} 4^{+} \mathrm{CD} 25^{-} \mathrm{Foxp} 3^{+}$Treg cells accompanied by high levels of IL-10 and TGF- $\beta$. The similar Treg responses induced by immunization of T. spiralis AES and MES indicated that T. spiralis infection induces differentiation of Treg through parasite-ES antigens. Both T. spiralis AES and MES could activate BMDCs in vitro to facilitate their maturation and to create regulatory cytokines IL-10 and TGF- $\beta$. The T. spiralis AES- and MES-pulsed DCs possess the abilities not only to present antigens to sensitized $\mathrm{CD} 4^{+} \mathrm{T}$ cells to stimulate their proliferation but also to induce naive $\mathrm{CD}^{+} \mathrm{T}$ cell to differentiate to Treg secreting IL-10 and TGF- $\beta$. The passive transfer of T. spiralis AES- and MES-pulsed BMDCs gives naive mice the ability to differentiate Treg cells. T. spiralis AES has a greater ability to induce Treg than MES does, but the latter has the ability to induce $\mathrm{CD} 4^{+} \mathrm{CD} 25^{-} \mathrm{Foxp}^{+}$Treg cells. The results obtained in this study suggested that T. spiralis ES products stimulate the differentiation of host regulatory $\mathrm{T}$ cells possibly through activating dendritic cells to create a regulatory environment that benefits the survival of the parasite in the host. However, the T. spiralis ES product-induced BMDC differentiation into the regulatory environment observed in in vitro experiments should be further confirmed by DC stimulation in vivo, and the specific components in the T. spiralis ES products that play these roles should be further investigated.

Supplementary Materials: The following are available online at http://www.mdpi.com/2073-4409/8/11/1404/s1, Figure S1: Th2, Treg, Th1, and Th17 CD4 ${ }^{+} \mathrm{T}$ cells from the spleen at different stages post T. spiralis infection (intestinal phase, day 6; NBL migration, day 15; larva capsule, day 30; and convalescent phase, day 60) were measured by FACS; Figure S2: Mouse BMDCs surface markers (CD40, CD80, CD86, and MHC II) were detected by FACS after which were pulsed with PBS, BSA, LPS, MES, or AES for 48 h. Figure S3: SDS-PAGE profiles of ES antigen of T. spiralis.

Author Contributions: Conceptualization, X.-M.S.; data curation, X.-M.S., K.G., C.-Y.H., and J.-J.H.; formal analysis, X.-M.S., K.G., C.-Y.H., and B.Z.; writing-original draft, X.-M.S., K.G., and X.Z.; writing-review and editing, B.Z. and X.Z.

Funding: This study was supported by grants from the National Natural Science Foundation of China (81772213, 81401681, and 81672042) and from the Natural Science Foundation of Beijing Municipality (7144192). 
Acknowledgments: We thank Yuan Gu, Yuli Cheng, Qing Sun, and Sha Liu from the Department of Medical Microbiology and Parasitology, School of Basic Medical Sciences, Capital Medical University, Beijing, China for all their invaluable efforts and technical assistance.

Conflicts of Interest: The authors declare no conflict of interest. The funders had no role in the design of the study; in the collection, analyses, or interpretation of data; in the writing of the manuscript; or in the decision to publish the results.

\section{References}

1. Boyton, R.J.; Altmann, D.M. Is selection for TCR affinity a factor in cytokine polarization? Trends Immunol. 2002, 23, 526-529. [CrossRef]

2. Ilic, N.; Gruden-Movsesijan, A.; Sofronic-Milosavljevic, L. Trichinella spiralis: Shaping the immune response. Immunol. Res. 2012, 52, 111-119. [CrossRef] [PubMed]

3. Velavan, T.P.; Ojurongbe, O. Regulatory T cells and parasites. J. Biomed. Biotechnol. 2011, 2011, 520940. [CrossRef] [PubMed]

4. Shevach, E.M. Mechanisms of foxp3+ T regulatory cell-mediated suppression. Immunity 2009, 30, 636-645. [CrossRef]

5. Maruyama, T.; Konkel, J.E.; Zamarron, B.F.; Chen, W. The molecular mechanisms of Foxp3 gene regulation. Semin. Immunol. 2011, 23, 418-423. [CrossRef]

6. Gao, Y.; Lin, F.; Su, J.; Gao, Z.; Li, Y.; Yang, J.; Deng, Z.; Liu, B.; Tsun, A.; Li, B. Molecular mechanisms underlying the regulation and functional plasticity of FOXP3(+) regulatory T cells. Genes Immun. 2012, 13, 1-13. [CrossRef]

7. Miyara, M.; Sakaguchi, S. Natural regulatory T cells: Mechanisms of suppression. Trends Mol. Med. 2007, 13, 108-116. [CrossRef]

8. Mold, J.E.; Michaelsson, J.; Burt, T.D.; Muench, M.O.; Beckerman, K.P.; Busch, M.P.; Lee, T.H.; Nixon, D.F.; McCune, J.M. Maternal alloantigens promote the development of tolerogenic fetal regulatory T cells in utero. Science 2008, 322, 1562-1565. [CrossRef]

9. Lan, R.Y.; Ansari, A.A.; Lian, Z.X.; Gershwin, M.E. Regulatory T cells: Development, function and role in autoimmunity. Autoimmun. Rev. 2005, 4, 351-363. [CrossRef]

10. Sakaguchi, S.; Yamaguchi, T.; Nomura, T.; Ono, M. Regulatory T cells and immune tolerance. Cell 2008, 133, 775-787. [CrossRef]

11. Finney, C.A.; Taylor, M.D.; Wilson, M.S.; Maizels, R.M. Expansion and activation of CD4(+)CD25(+) regulatory T cells in Heligmosomoides polygyrus infection. Eur. J. Immunol. 2007, 37, 1874-1886. [CrossRef] [PubMed]

12. Wen, X.; He, L.; Chi, Y.; Zhou, S.; Hoellwarth, J.; Zhang, C.; Zhu, J.; Wu, C.; Dhesi, S.; Wang, X.; et al. Dynamics of Th17 cells and their role in Schistosoma japonicum infection in C57BL/6 mice. PLoS Negl. Trop. Dis. 2011, 5, e1399. [CrossRef] [PubMed]

13. Baumgart, M.; Tompkins, F.; Leng, J.; Hesse, M. Naturally occurring CD4+Foxp3+ regulatory T cells are an essential, IL-10-independent part of the immunoregulatory network in Schistosoma mansoni egg-induced inflammation. J. Immunol. 2006, 176, 5374-5387. [CrossRef] [PubMed]

14. McSorley, H.J.; Harcus, Y.M.; Murray, J.; Taylor, M.D.; Maizels, R.M. Expansion of Foxp3+ regulatory T cells in mice infected with the filarial parasite Brugia malayi. J. Immunol. 2008, 181, 6456-6466. [CrossRef] [PubMed]

15. Yang, J.; Pan, W.; Sun, X.; Zhao, X.; Yuan, G.; Sun, Q.; Huang, J.; Zhu, X. Immunoproteomic profile of Trichinella spiralis adult worm proteins recognized by early infection sera. Parasit. Vectors 2015, 8, 20. [CrossRef] [PubMed]

16. Wu, Z.; Sofronic-Milosavljevic, L.; Nagano, I.; Takahashi, Y. Trichinella spiralis: Nurse cell formation with emphasis on analogy to muscle cell repair. Parasit. Vectors 2008, 1, 27. [CrossRef]

17. Else, K.J. Have gastrointestinal nematodes outwitted the immune system? Parasit. Immunol. 2005, 27, 407-415. [CrossRef]

18. Zhang, Z.; Yang, J.; Wei, J.; Yang, Y.; Chen, X.; Zhao, X.; Gu, Y.; Cui, S.; Zhu, X. Trichinella spiralis paramyosin binds to $\mathrm{C} 8$ and $\mathrm{C} 9$ and protects the tissue-dwelling nematode from being attacked by host complement. PLoS Negl. Trop. Dis. 2011, 5, e1225. [CrossRef]

19. Zhao, X.; Hao, Y.; Yang, J.; Gu, Y.; Zhu, X. Mapping of the complement C9 binding domain on Trichinella spiralis paramyosin. Parasit. Vectors 2014, 7, 80. [CrossRef] 
20. Sun, R.; Zhao, X.; Wang, Z.; Yang, J.; Zhao, L.; Zhan, B.; Zhu, X. Trichinella spiralis Paramyosin Binds Human Complement C1q and Inhibits Classical Complement Activation. PLoS Negl. Trop. Dis. 2015, 9, e4310. [CrossRef]

21. Zhao, L.; Shao, S.; Chen, Y.; Sun, X.; Sun, R.; Huang, J.; Zhan, B.; Zhu, X. Trichinella spiralis Calreticulin Binds Human Complement C1q As an Immune Evasion Strategy. Front. Immunol. 2017, 8, 636. [CrossRef] [PubMed]

22. Guo, K.; Sun, X.; Gu, Y.; Wang, Z.; Huang, J.; Zhu, X. Trichinella spiralis paramyosin activates mouse bone marrow-derived dendritic cells and induces regulatory T cells. Parasit. Vectors 2016, 9, 569. [CrossRef] [PubMed]

23. Yang, X.; Yang, Y.; Wang, Y.; Zhan, B.; Gu, Y.; Cheng, Y.; Zhu, X. Excretory/secretory products from Trichinella spiralis adult worms ameliorate DSS-induced colitis in mice. PLoS ONE 2014, 9, e96454. [CrossRef] [PubMed]

24. Gu, Y.; Wei, J.; Yang, J.; Huang, J.; Yang, X.; Zhu, X. Protective immunity against Trichinella spiralis infection induced by a multi-epitope vaccine in a murine model. PLoS ONE 2013, 8, e77238. [CrossRef] [PubMed]

25. Martinez-Gomez, F.; Santiago-Rosales, R.; Ramon, B.C. Effect of Lactobacillus casei Shirota strain intraperitoneal administration in CD1 mice on the establishment of Trichinella spiralis adult worms and on IgA anti-T spiralis production. Vet. Parasitol. 2009, 162, 171-175. [CrossRef] [PubMed]

26. Ilic, N.; Worthington, J.J.; Gruden-Movsesijan, A.; Travis, M.A.; Sofronic-Milosavljevic, L.; Grencis, R.K. Trichinella spiralis antigens prime mixed Th1/Th2 response but do not induce de novo generation of Foxp3+ T cells in vitro. Parasit. Immunol. 2011, 33, 572-582. [CrossRef]

27. Dea-Ayuela, M.A.; Rama-Iniguez, S.; Bolas-Fernandez, F. Vaccination of mice against intestinal Trichinella spiralis infections by oral administration of antigens microencapsulated in methacrilic acid copolymers. Vaccine 2006, 24, 2772-2780. [CrossRef]

28. Livak, K.J.; Schmittgen, T.D. Analysis of relative gene expression data using real-time quantitative PCR and the 2(-Delta Delta C(T)) Method. Methods 2001, 25, 402-408. [CrossRef]

29. Taylor, M.D.; LeGoff, L.; Harris, A.; Malone, E.; Allen, J.E.; Maizels, R.M. Removal of regulatory T cell activity reverses hyporesponsiveness and leads to filarial parasite clearance in vivo. J. Immunol. 2005, 174, 4924-4933. [CrossRef]

30. Yu, Y.R.; Deng, M.J.; Lu, W.W.; Jia, M.Z.; Wu, W.; Qi, Y.F. Systemic cytokine profiles and splenic toll-like receptor expression during Trichinella spiralis infection. Exp. Parasitol. 2013, 134, 92-101. [CrossRef]

31. Steel, N.; Faniyi, A.A.; Rahman, S.; Swietlik, S.; Czajkowska, B.I.; Chan, B.T.; Hardgrave, A.; Steel, A.; Sparwasser, T.D.; Assas, M.B.; et al. TGFbeta-activation by dendritic cells drives Th17 induction and intestinal contractility and augments the expulsion of the parasite Trichinella spiralis in mice. PLoS Pathog. 2019, 15, e1007657. [CrossRef] [PubMed]

32. Bettelli, E.; Carrier, Y.; Gao, W.; Korn, T.; Strom, T.B.; Oukka, M.; Weiner, H.L.; Kuchroo, V.K. Reciprocal developmental pathways for the generation of pathogenic effector TH17 and regulatory T cells. Nature 2006, 441, 235-238. [CrossRef] [PubMed]

33. Beiting, D.P.; Gagliardo, L.F.; Hesse, M.; Bliss, S.K.; Meskill, D.; Appleton, J.A. Coordinated control of immunity to muscle stage Trichinella spiralis by IL-10, regulatory T cells, and TGF-beta. J. Immunol. 2007, 178, 1039-1047. [CrossRef] [PubMed]

34. Bai, X.; Wu, X.; Wang, X.; Guan, Z.; Gao, F.; Yu, J.; Yu, L.; Tang, B.; Liu, X.; Song, Y.; et al. Regulation of cytokine expression in murine macrophages stimulated by excretory/secretory products from Trichinella spiralis in vitro. Mol. Cell. Biochem. 2012, 360, 79-88. [CrossRef] [PubMed]

35. Moll, H. Dendritic cells and host resistance to infection. Cell. Microbiol. 2003, 5, 493-500. [CrossRef] [PubMed]

36. Terrazas, C.A.; Alcantara-Hernandez, M.; Bonifaz, L.; Terrazas, L.I.; Satoskar, A.R. Helminth-excreted/secreted products are recognized by multiple receptors on DCs to block the TLR response and bias Th2 polarization in a cRAF dependent pathway. FASEB J. 2013, 27, 4547-4560. [CrossRef] [PubMed]

37. Hu, W.; Jain, A.; Gao, Y.; Dozmorov, I.M.; Mandraju, R.; Wakeland, E.K.; Pasare, C. Differential outcome of TRIF-mediated signaling in TLR4 and TLR3 induced DC maturation. Proc. Natl. Acad. Sci. USA 2015, 112, 13994-13999. [CrossRef]

38. Van Riet, E.; Hartgers, F.C.; Yazdanbakhsh, M. Chronic helminth infections induce immunomodulation: Consequences and mechanisms. Immunobiology 2007, 212, 475-490. [CrossRef] 
39. Cervi, L.; MacDonald, A.S.; Kane, C.; Dzierszinski, F.; Pearce, E.J. Cutting edge: Dendritic cells copulsed with microbial and helminth antigens undergo modified maturation, segregate the antigens to distinct intracellular compartments, and concurrently induce microbe-specific Th1 and helminth-specific Th2 responses. J. Immunol. 2004, 172, 2016-2020. [CrossRef]

40. Maizels, R.M.; Yazdanbakhsh, M. Immune regulation by helminth parasites: Cellular and molecular mechanisms. Nat. Rev. Immunol. 2003, 3, 733-744. [CrossRef]

41. Wu, Y.; Bastian, D.; Schutt, S.; Nguyen, H.; Fu, J.; Heinrichs, J.; Xia, C.; Yu, X.Z. Essential Role of Interleukin-12/23p40 in the Development of Graft-versus-Host Disease in Mice. Biol. Blood Marrow Transplant. 2015, 21, 1195-1204. [CrossRef] [PubMed]

42. Ilic, N.; Gruden-Movsesijan, A.; Cvetkovic, J.; Tomic, S.; Vucevic, D.B.; Aranzamendi, C.; Colic, M.; Pinelli, E.; Sofronic-Milosavljevic, L. Trichinella spiralis Excretory-Secretory Products Induce Tolerogenic Properties in Human Dendritic Cells via Toll-Like Receptors 2 and 4. Front. Immunol. 2018, 9, 11. [CrossRef] [PubMed]

43. Leech, M.D.; Grencis, R.K. Induction of enhanced immunity to intestinal nematodes using IL-9-producing dendritic cells. J. Immunol. 2006, 176, 2505-2511. [CrossRef] [PubMed]

44. Fang, L.; Sun, L.; Yang, J.; Gu, Y.; Zhan, B.; Huang, J.; Zhu, X. Heat shock protein 70 from Trichinella spiralis induces protective immunity in BALB/c mice by activating dendritic cells. Vaccine 2014, 32, 4412-4419. [CrossRef]

45. Helft, J.; Bottcher, J.; Chakravarty, P.; Zelenay, S.; Huotari, J.; Schraml, B.U.; Goubau, D.; Reis, E.S.C. GM-CSF Mouse Bone Marrow Cultures Comprise a Heterogeneous Population of CD11c(+)MHCII(+) Macrophages and Dendritic Cells. Immunity 2015, 42, 1197-1211. [CrossRef]

46. Steinman, R.M.; Hawiger, D.; Nussenzweig, M.C. Tolerogenic dendritic cells. Annu. Rev. Immunol. 2003, $21,685-711$. [CrossRef]

47. Maldonado, R.A.; von Andrian, U.H. How tolerogenic dendritic cells induce regulatory T cells. Adv. Immunol. 2010, 108, 111-165. [CrossRef]

48. Fontenot, J.D.; Gavin, M.A.; Rudensky, A.Y. Foxp3 programs the development and function of CD4+CD25+ regulatory T cells. Nat. Immunol. 2003, 4, 330-336. [CrossRef]

49. Fontenot, J.D.; Rasmussen, J.P.; Williams, L.M.; Dooley, J.L.; Farr, A.G.; Rudensky, A.Y. Regulatory T cell lineage specification by the forkhead transcription factor foxp3. Immunity 2005, 22, 329-341. [CrossRef]

50. Sofronic-Milosavljevic, L.J.; Radovic, I.; Ilic, N.; Majstorovic, I.; Cvetkovic, J.; Gruden-Movsesijan, A. Application of dendritic cells stimulated with Trichinella spiralis excretory-secretory antigens alleviates experimental autoimmune encephalomyelitis. Med. Microbiol. Immunol. 2013, 202, 239-249. [CrossRef]

51. Yang, J.; Yang, Y.; Gu, Y.; Li, Q.; Wei, J.; Wang, S.; Boireau, P.; Zhu, X. Identification and characterization of a full-length cDNA encoding paramyosin of Trichinella spiralis. Biochem. Biophys. Res. Commun. 2008, 365, 528-533. [CrossRef] [PubMed]

(C) 2019 by the authors. Licensee MDPI, Basel, Switzerland. This article is an open access article distributed under the terms and conditions of the Creative Commons Attribution (CC BY) license (http://creativecommons.org/licenses/by/4.0/). 